\begin{tabular}{|c|c|c|}
\hline Beitr. Ent. & Keltern & ISSN 0005-805X \\
\hline $\mathbf{6 0}(2010) 1$ & S. $195-212$ & 31.07 .2010 \\
\hline
\end{tabular}

\title{
New taxa of Campylomyzini and Pteridomyiini from Tasmania
}

\section{(Diptera: Cecidomyiidae: Micromyinae)}

With 9 figures

Mathias Jaschhof \& Catrin Jaschhof

\section{Summary}

The following new taxa of Micromyinae are described from Tasmania: Warramyia weldensis JaschHof gen. et sp. n. (in Campylomyzini); Pteridomyia tasmanica Jaschrof sp. n.; Pseudomonardia dorani JaschHor sp. n.; Pseudomonardia niklasi Jaschrof sp. n.; Pseudomonardia tobiasi Jaschiof sp. n.; Pseudomonardia dawnae JaschHof sp. n.; and Hintelmannomyia aestimata JasChHoF gen. et sp. n. (all in Pteridomyiini). Campylomyza grandiuscula SKUSE, 1890, which is actually a species of the genus Pteridomyia JaschHOF, 2003, is redescribed on the basis of the holotype and the male terminalia are figured for the first time. A key to the Tasmanian species of Pseudomonardia is provided.

\section{Zusammenfassung}

Die folgenden neuen Taxa der Micromyinae werden aus Tasmanien beschrieben: Warramyia weldensis JASCHHOF gen. et sp. n. (innerhalb der Campylomyzini), Pteridomyia tasmanica JaschHof sp. n., Pseudomonardia dorani Jaschrof sp. n., Pseudomonardia niklasi Jaschiof sp. n., Pseudomonardia tobiasi Jaschhof sp. n., Pseudomonardia dawnae JASCHHOF sp. n. und Hintelmannomyia aestimata JASCHHOF gen. et sp. n. (alle innerhalb der Pteridomyiini). Campylomyza grandiuscula Sкuse, 1890, tatsächlich eine Art der Gattung Pteridomyia JASCHнOF, 2003, wird nachbeschrieben, und der männliche Genitalapparat wird erstmalig abgebildet. Ein Bestimmungsschlüssel für die tasmanischen Pseudomonardia-Arten wird zur Verfügung gestellt.

Key words

Diptera, Cecidomyiidae, Micromyinae, Australia, Tasmania, Campylomyzini, Pteridomyiini, new genera, new species

\section{Introduction}

With this article we continue the taxonomic treatment of Australian Micromyinae, which is mainly based on specimens from Tasmania. A previous contribution has treated the tribe Peromyiini (Jaschrof 2010). The two tribes dealt with here, Campylomyzini and Pteridomyiini, have thus far been unknown to occur in Tasmania. Campylomyzini are to our knowledge very sparsely represented in the southern hemisphere (JAsChHOF \& JAsChноғ 2009), with no indigenous species previously known from the Australasian Region (Jaschноғ \& Jaschноғ 2003). We found a single new campylomyzine species in our samples from Tasmania, which due to its peculiar adult morphology is classified in a genus of its own. Pteridomyiini, first described from New Zealand and shown to constitute a major component of the local micromyine fauna, were anticipated to occur in other Gondwanan landmasses (Jaschнof \& Jaschноғ 2004). As recently shown (Jaschrof 2010), there is a mainland Australian pteridomyiine, Pteridomyia grandiuscula (Skuse, 
1890), among the species SKUSE (1890) had erroneously described in the genus Campylomyza Meigen, 1818. Here we document the presence in Tasmania of three pteridomyiine genera: Pteridomyia Jaschnof, 2003, Pseudomonardia Jaschнof, 2003, both known from New Zealand, and a new genus containing a single new species. We name and describe the new taxa, altogether 2 new genera and 7 new species, and discuss their systematic position within the Micromyidi, which is the supertribe containing the great majority of world Micromyinae tribes, genera and species (Jaschnof \& Jaschnof 2009). Pteridomyia grandiuscula is redescribed, based on the holotype male of which the terminalia are figured here for the first time.

\section{Material and methods}

As with a previous study of Australian Micromyinae (JaschHof 2010), specimens come from the Tasmanian Forest Insect Collection in the care of Forestry Tasmania, Hobart, and from the Naturhistoriska Riksmuseet Stockholm (NHRS), Sweden. The specimens previously stored in $70 \%$ ethanol were slide-mounted for compound microscope study. As regards the mounting technique, as well as Micromyinae morphological terminology and classification, the reader is referred to JaschHof \& JaschHof (2009). New taxa described in the present paper are attributed to the senior author. Holotypes will be deposited with the Australian Museum, Sydney (AMS), paratypes with the AMS, NHRS and Senckenberg Deutsches Entomologisches Institut, Müncheberg (SDEI), other voucher specimens with the NHRS and SDEI. The holotype of Campylomyza grandiuscula was lent by the Australian National Insect Collection, Canberra (ANIC).

\section{Taxonomy}

\section{Tribus Campylomyzini KLeEsattel, 1979}

\section{Genus Warramyia JaSCHнOF gen. n.}

Type species: Warramyia weldensis JAschHOF sp. n., described below.

\section{Diagnosis:}

Based on male adult, females and immatures remain unknown. The new genus differs from all other Micromyidi (i.e., Micromyinae with furcate $\mathrm{CuA}$ and usually 12 male antennal flagellomeres) in the presence of 1 sensory bud on basR1 (Fig. 1A) and a mesothoracal, acute-angled apodeme that is lacking or incomplete elsewhere (Fig. 1B, see Discussion). Among Campylomyzini, Warramyia is unusual for the complete lateral eye bridge, the very short apicR1, and the poorly developed M (Fig. 1A). Warramyia has collar-shaped antennal sensilla (Fig. 2B), which are also present in some other campylomyzine genera, and male terminalia which are similar to that in Neurolyga Rondani, 1840, with simple, hair-shaped antennal sensilla. The single species known of Warramyia, weldensis, is the smallest campylomyzine hitherto found.

\section{Description:}

Male. Body size: $<1.0 \mathrm{~mm}$. Head: Postfrons asetose. 3 ocelli. Occiput with sparse setae. 1 sparse row of postocular bristles. Eye bridge complete. Antennal scape and pedicel subequal in size, both setose. 8 flagellomeres retained, nodes with crenulate whorls of sensory hairs, on apical half hairshaped translucent sensilla laterally and 1 incomplete collar-shaped sensillum medially (Fig. 2B). Clypeus large. Maxillary palpus short, 4-segmented, with setae of various lengths including some short, stiff setae, first segment with hair-shaped translucent sensilla (Fig. 2C). 


\section{Thorax:}

Fig. 1B. Scutum and scutellum setose, otherwise asetose. Anterior basalare not shifted ventrally. Mesepimeron larger than laterotergite. Endomesothorax with closed, acute-angled apodeme situated above anterior portion of postphragma (see Discussion). Wing: Fig. 1A. Membrane with microtrichia and setae on both sides. Vein setae strongly reduced. Venation as typical of Micromyidi (JaschHof \& JASCHHOF 2009: fig. 15F), veins not as sharply demarcated from membrane as is usual in Micromyidi. Halter club-shaped, with very short stem, node with sparse, short setae. Legs: With long setae, true scales apparently lacking. Tarsi short compared with other Micromyidi. Pretarsal claws crescent-shaped, without teeth. Empodia as long as claws.

Preabdomen: Sclerotization generally very poor. Tergal setae much reduced. Tergal plaques absent. Pleura asetose. Terminalia: Fig. 2A. Tg9 very weak (not figured). Gonocoxites broadly fused ventrobasally, ventroapical margin emarginate, ventrobasal margin weak, dorsal transverse bridge extending far beyond ventral margin, antGA undeveloped. Gonostylus simple, without apical spine. Ejaculatory apodeme large, ducts of accessory glands indistinct. Tegmen largely membranous. Apices of ejaculatory apodeme and tegmen merged to form extensive membranous cupola. Cerci present as pair of ovate lobes attached to tg9. St10 absent.

\section{Discussion:}

The tribal assignment of this new genus is inherently difficult due to the regressive adult morphology of the single species included. Therefore, its classification with the Campylomyzini must be regarded as tentative. As outlined above, some characters of Warramyia are not found in other Campylomyzini, not even in other Micromyidi. No other micromyid is known in which the anterior basalare is in the original position, not shifted ventrally, which must be due to reversal. Other characters can be ascribed to miniaturization, such as the extremely short $\mathrm{M}$ and perhaps also the presence of a sensory bud on basR1, a vein that usually lacks sensory buds. The mesothoracic apodeme is supposed to be a new acquisition of Warramyia, since it is definitely absent in other Micromyinae and apparently also in other more primitive Cecidomyiidae, although the endoskeleton and musculature of Cecidomyiidae have never been systematically investigated. The dorsalmost and/or ventralmost sections of this apodeme can be identified in many other Micromyinae, but nowhere is the full angle developed. Reasons to classify Warramyia among Campylomyzini are the possession of collar-shaped antennal sensilla, which are present only in Campylomyzini and Micromyini; the absence of a sensory bud on $\mathrm{r}-\mathrm{m}$; the well developed mediotergite (both characters that argue against an affiliation with Micromyini); and the structure of the male genitalia, which are similar to those in Neurolyga.

\section{Etymology:}

The name refers to Warra with its marvellous indigenous Tasmanian forest and precious mature timber habitat. Warramyia is an especially remarkable component of the rich fauna of Cecidomyiidae and other Sciaroidea found at Warra.

\section{Warramyia weldensis JASCHHOF sp. $\mathbf{n}$.}

(Figs 1A-B, 2A-C)

\section{Description:}

Male. Body size: $0.8 \mathrm{~mm}$. Head: Eye bridge 2 ommatidia long laterally and 3-4 ommatidia dorsally. 4 postocular bristles. Neck of fourth antennal flagellomere as long as node; node with 1 whorl of short setae subbasally, 1 complete and 1 incomplete whorl of long sensory hairs, several hair-shaped translucent sensilla distolaterally, on first to fifth flagellomeres 1 incomplete collar-shaped sensillum 

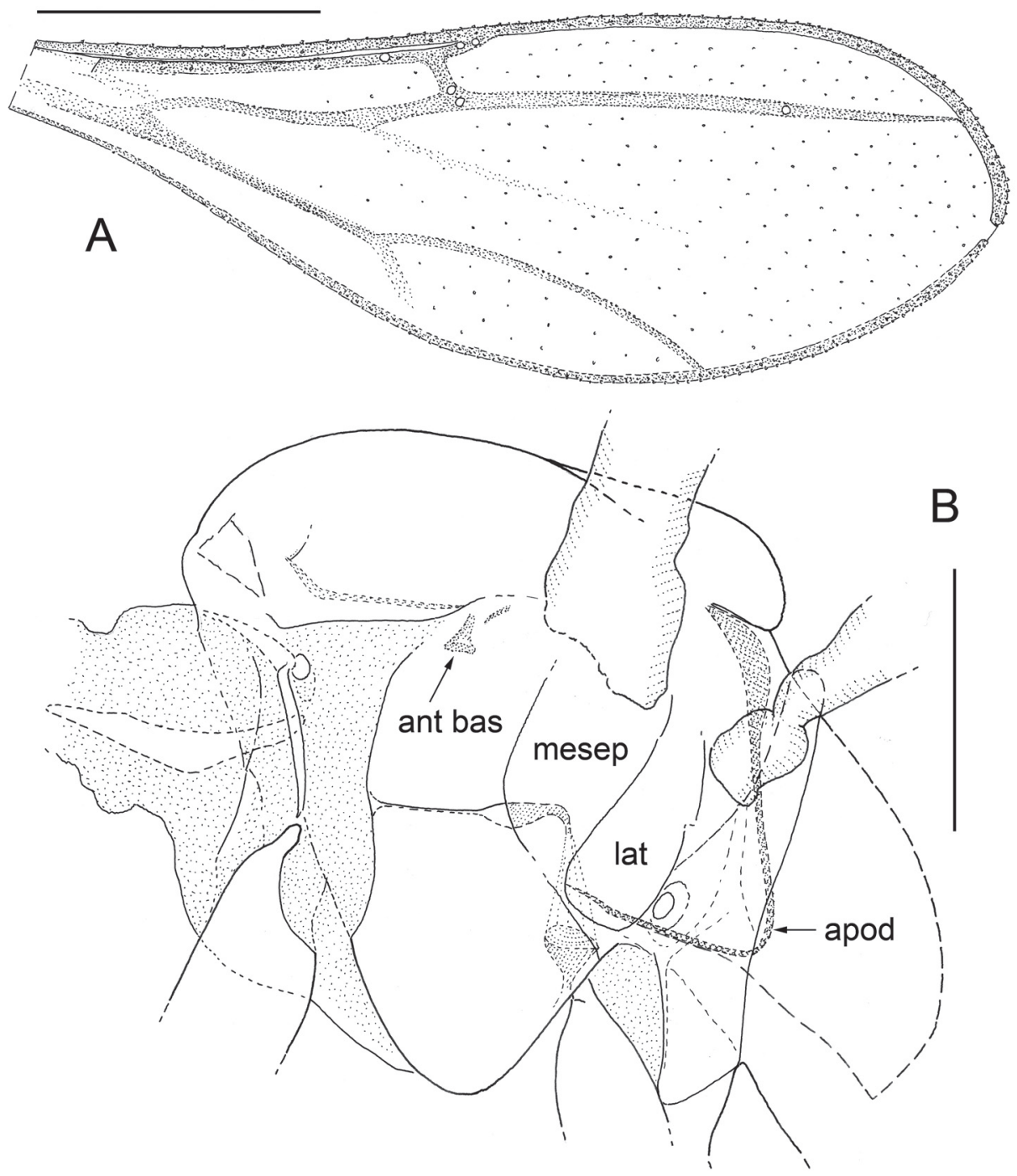

Fig. 1: Warramyia weldensis gen. et sp. n., male. - A: Wing, dorsal view; - B: Thorax, lateral view. Ant bas, anterior basalare; apod, apodeme; lat, laterotergite; mesep, mesepisternum. Scale bar $=0.2 \mathrm{~mm}(\mathrm{~A})$ and $0.1 \mathrm{~mm}(\mathrm{~B})$.

distomedially (Fig. 2B). First segment of maxillary palpus thickest of all segments, second segment almost globular, third and fourth segments short subcylindrical (Fig. 2C).

\section{Thorax:}

Fig. 1B. Scutum with sparse setae laterally and dorsocentrally. Wing: Fig. 1A. Narrow. Dorsal setae only on basR1, no ventral setae. Setae on membrane petering out towards wing base. Pattern of sensory buds: basR1, 1; apicR1, 2; Rs, 1; R5 basally, 1; R5 distally, 1. Costal cell extremely small. Costal break present. ApicR1 as long as Rs. M vestigial. CuA2 short and weak.

Preabdomen: Segment 1 and tergum 2 asetose. Terga 3-8 with few lateral and single dorsal setae. 


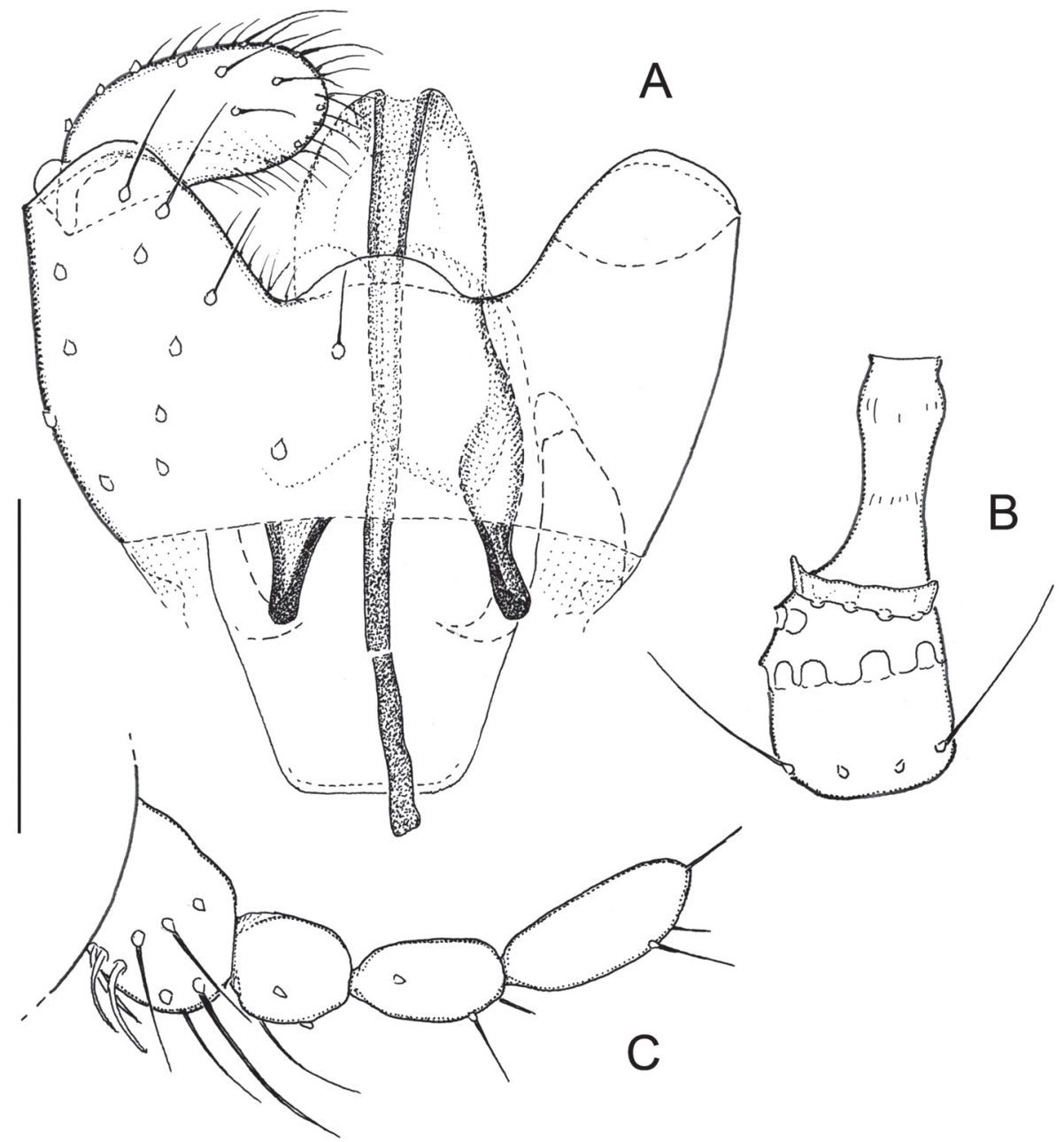

Fig. 2: Warramyia weldensis gen. et sp. n., male. - A: Terminalia, ventral view; - B: Fourth antennal flagellomere, medial view; - C: Maxillary palpus, lateral view. Scale bar $=0.05 \mathrm{~mm}$.

Terga 6-8 sclerotized. Sterna 2-8 setose. Terminalia: Fig. 2A. Tg9 subtrapezoid, apparently asetose (not figured). Gonocoxites with a few short setae, ventroapical margin with wide emargination, a small bare membranous lobe medially. Gonostylus subcylindrical, with a few short setae and numerous large microtrichia, especially on apical half. Ejaculatory apodeme longer than gonocoxites and tegmen, strongly sclerotized, slightly widened towards apex. Tegmen large, longer than gonocoxites, slightly constricted medially, largely membranous, parameral apodemes sclerotized. Cerci with large microtrichia, no setae.

\section{Etymology:}

The name is derived from Mount Weld, the type-locality.

\section{Types:}

Holotype: Male, Australia, Tasmania, Warra LTER site, Mt Weld, 100 m a.s.l., 27 Feb. 2001, Malaise sample FT19, N. Doran \& R. Bashford (in AMS). 
Tribus Pteridomyiini JasChHOF, 2003

Genus Pteridomyia JaschHof, 2003

Jaschнof \& Jaschiof 2003: 111.

\section{Pteridomyia tasmanica Jaschноғ sp. $\mathbf{n}$.}

(Fig. 3A-E)

\section{Diagnosis:}

The tegmen of Pteridomyia tasmanica has a pair of membranous ovate folds apically (Fig. 3C) while lacking the pair of sclerotized subtriangular ventral processes present in the other three Pteridomyia species, two in New Zealand (JAsChноғ \& JAsснно 2003) and one in mainland Australia (see below).

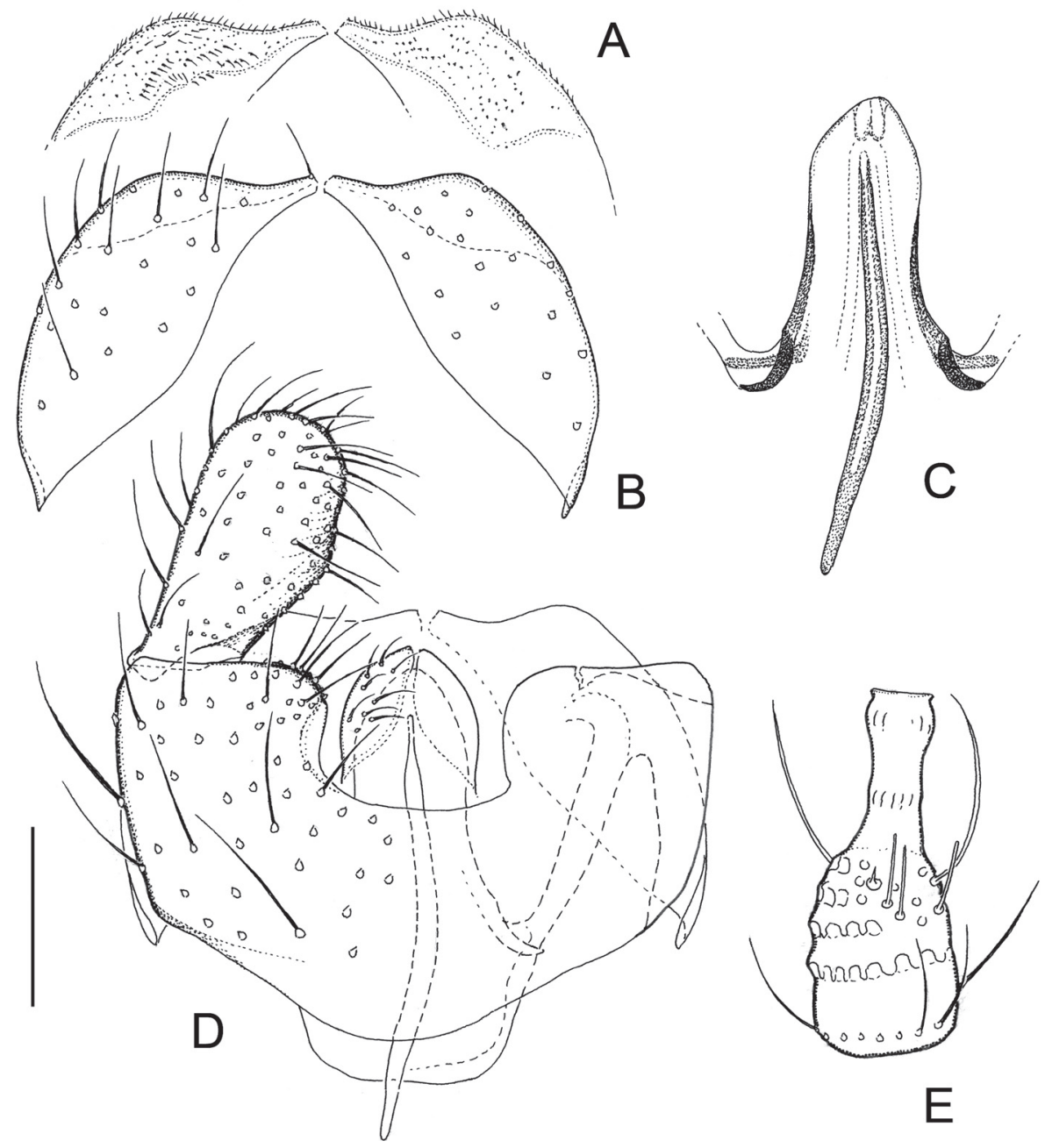

Fig. 3: Pteridomyia tasmanica sp. n., male. - A: Apical portion of ninth tergite, ventral view; - B: Ninth tergite, dorsal view; - C: Ejaculatory apodeme and tegmen, ventral view; - D: Terminalia, ventral view; - E: Fourth antennal flagellomere, lateral view. Scale bar $=0.05 \mathrm{~mm}$. 


\section{Description:}

Characters not mentioned are in accordance with the generic description (JASCHHOF \& JASCHHOF 2003). Male. Body size: $1.2 \mathrm{~mm}$. Head: Eye bridge 4-5 ommatidia long. 1 row of 3-4 postocular bristles. Neck of fourth antennal flagellomere shorter than node; node with 1 single to double whorl of short setae subbasally, 1 complete and 3 incomplete whorls of long sensory hairs, several hair-shaped translucent sensilla on apical half (Fig. 3E).

\section{Thorax:}

Preepisternum 2 asetose. Wing: ApicR1 = 3 times the length of Rs. Veins devoid of ventral setae. Pattern of sensory buds: apicR1, 3; Rs or R5 basally, 1; r-m, 1; R5 medially/distally, 2. Legs: Pretarsal claws with 2-3 fine teeth behind subapical swelling. Empodia barely as long as claws. Preabdomen: Tergites 2-8 short, slightly longer laterally than dorsally, situated on anterior margin of terga, with sparse setae laterally. Tergal plaques absent. Sternites 2-8 each with membranous transverse band, setose. Pleura asetose. Terminalia: $\operatorname{Tg} 9$ subtrapezoid, very short medially, not interrupted (broken in the one specimen studied), evenly setose (Fig. 3B), with pubescent lobes on ventral side apicolaterally (Fig. 3A). Gonocoxites with moderately long, U-shaped ventral emargination, laterally of emargination a small, densely setose protrusion; dorsal transverse bridge extending beyond ventral margin; antGA undeveloped (Fig. 3D). Gonostylus large, subcylindrical, broadly rounded apically, directed ventromedially (Fig. 3D). Ejaculatory apodeme longer than tegmen, sclerotized, ducts of accessory glands well visible (Fig. 3C). Tegmen as long as gonocoxites, tapered towards narrowly rounded apex, largely membranous, with 1 pair of membranous ovate folds apically, parameral apodemes sclerotized (Fig. 3C). Tegmen apex wrapped by cerci, these with dense, short setae directed ventrally (Fig. 3D).

Female and immature stages. Unknown.

\section{Discussion:}

The new species is assigned to the genus Pteridomyia by reason of its male genitalic structures, even though $P$. tasmanica must be regarded as a rather untypical member. The ventroapical lobes on the gonocoxites of $P$. tasmanica are vestigial compared with those in both $P$. gressitti (Yukawa, 1964) and P. bilobata JaschHof, 2003 from New Zealand. The pubescent lobes ventrally on the ninth tergite are similar to those in the other Pteridomyia species. As regards tegmen structure, we suggest the pair of membranous folds present in P. tasmanica is homologous to the pair of sclerotized processes present in the other Pteridomyia species.

\section{Etymology:}

The name is derived from Tasmania where the specimen was collected.

Holotype: Male, Australia, Tasmania, Warra LTER site, Manuka Road, 14 April 2000, Malaise sample FT28645, R. BASHFORD (in AMS).

\section{Pteridomyia grandiuscula (SKUSE, 1890)}

SKUSE 1890: 388 .

(Fig. 4A-C)

All that is known of this species is SKUSE's description, which fails to mention characters specific to any micromyine genus or species, and the male holotype, which is in poor condition (cf. JAschно 2010). Fortunately the terminalia are well preserved so they can be described and 


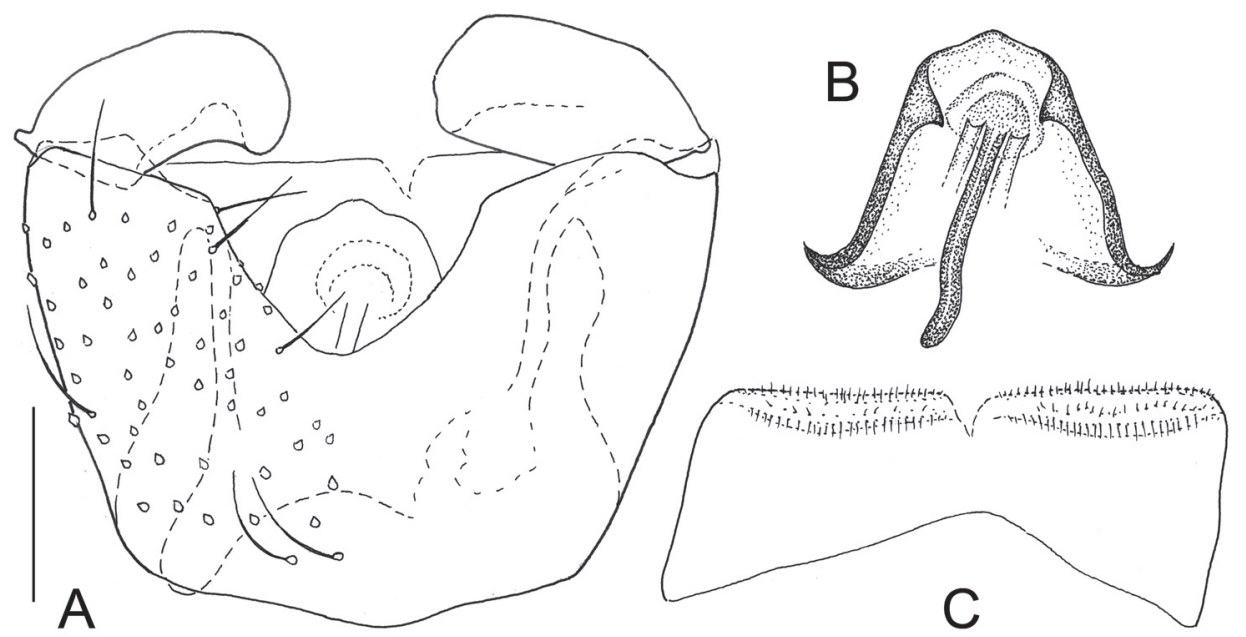

Fig. 4: Pteridomyia grandiuscula (Skuse), holotype male. - A: Terminalia, ventral view; - B: Ejaculatory apodeme and tegmen, ventral view; - C: Ninth tergite, ventral view. Scale bar $=0.05 \mathrm{~mm}$.

figured here. Meanwhile we have to watch out for fresh specimens needed to amend the species description regarding characters other than male genitalia.

\section{Diagnosis:}

The tegmen in Pteridomyia grandiuscula is shorter than wide and equipped with a pair of subtriangular processes subapicolaterally (Fig. 4B). Similar processes are also present in $P$. gressitti and P. bilobata in which, however, the tegmen is longer than wide.

\section{Redescription:}

Male. Body size: $>1.0 \mathrm{~mm}$.

Terminalia: $\operatorname{Tg} 9$ subtrapezoid, evenly setose dorsally, with pubescent lobes ventrally along apical margin (Fig. 4C). Gonocoxites with moderately long, V-shaped ventral emargination, laterally of emargination a small protrusion; dorsal transverse bridge not extending beyond ventral margin; antGA largely developed (retained only on left side, Fig. 4A). Gonostyli deformed, subcylindrical or slightly curved inwards, apparently slightly excavated dorsomedially, no apical spine (Fig. $4 \mathrm{~A})$. Ejaculatory apodeme as long as tegmen, sclerotized, ducts of accessory glands distinctive, aedeagus head a slightly sclerotized plate (Fig. 4B). Tegmen shorter than gonocoxites, shorter than wide, tapered towards apex, slightly sclerotized, with 1 pair of small subtriangular processes subapicolaterally (Fig. 4B). Cerci with short setae (not figured). St10 absent.

Female and immature stages. Unknown.

\section{Genus Pseudomonardia JasCHноғ, 2003}

JASCHHOF \& JASCHHOF 2003: 115.

None of the 4 species of Pseudomonardia described here from Tasmania is identical to any of the 11 species previously named from New Zealand (JAsChHof \& JASCHнof 2003). The key presented here covers only the species from Tasmania. Key users have to consider, however, that we know of several other Tasmanian species of Pseudomonardia, of which our specimens are insufficient for description, including 1 or 2 species that are very similar to the New Zealand $P$. communis 
JASCHHOF, 2003. In addition, we have seen a specimen of an unnamed species from mainland Australia (Queensland). The species descriptions given below refer only to those character states that differ from the generic diagnosis by JASCHHOF \& JASCHHOF (2003).

\section{Key to the species in Tasmania (males)}

1 Maxillary palpus 3-segmented. Neck of fourth antennal flagellomere longer than node .. P. dawnae JаSCHнOF sp. $\mathrm{n}$.

- $\quad$ Maxillary palpus 4-segmented. Neck of fourth antennal flagellomere shorter than node

2 Gonostylus with 1 pointed spine apically and 1 flat rounded spine dorsosubapically, the apical spine thick (Fig. 7A-B) P. tobiasi JAsCHHOF sp. $\mathrm{n}$.

- Gonostylus with 1 thin spine apically (Figs 5A, 6A) 3

3 Gonostylus elongate and slender (Fig. 5A). Tegmen evenly tapered towards apex (Fig. 5C) P. dorani JASCHHOF sp. n.

- $\quad$ Gonostylus thick, with strongly convex outer margin (Fig. 6A). Tegmen slightly constricted subapically (Fig. 6B) P. niklasi JaschHоF sp. n.

\section{Pseudomonardia dorani JASCHHOF sp. n.}

(Fig. 5A-C)

\section{Diagnosis:}

This species belongs to the informal group of pseudomonardias in which the gonocoxite emargination is U-shaped and the apical gonostylus spine is present (see JASCHHOF \& JASCHHOF 2003: 115f.). There are 3 such species in New Zealand (P. communis, P. parva JAschHof, 2003, and $P$. elongata JAschHof, 2003) and 2 in Tasmania (P. dorani, P. niklasi sp. n.). Among these, P. dorani is the only species in which the gonostyli are elongate and slender, and the gonostylus spine is situated truly apically (Fig. 5A).

\section{Description:}

Male. Body size: 0.9-1.1 mm. Head: Postfrons asetose. Eye bridge 2-4 ommatidia long. 4-8 postocular bristles. Neck of fourth antennal flagellomere shorter than node; node with 1 double whorl of setae subbasally, 1 complete and 3-4 incomplete whorls of long sensory hairs, several hair-shaped translucent sensilla on apical half (Fig. 5B). Maxillary palpus 4-segmented, long and slender, fourth segment usually much longer than third.

Wing: ApicR1 = 3.5-4.0 times the length of Rs. CuA2 very short. R5 without ventral setae. Legs: Pretarsal claws with 3 fine teeth behind subapical swelling. Empodia 1/3 as long as claws.

Terminalia: $\mathrm{Tg} 9$ short, subtrapezoid, evenly setose (Fig. 5A). Gonocoxites with broad U-shaped, moderately deep emargination, below emargination a subtriangular membranous portion without setae; antGA well developed, pointing anterolaterally (Fig. 5A). Gonostylus slender, tapered towards apex, apical portion curved inwards, 1 slender pointed spine apically, 1 short stiff subapical bristle dorsally, another such bristle on outer margin (Fig. 5A). Ejaculatory apodeme thin, slightly shorter than tegmen (Fig. 5C). Aedeagus head fully membranous, accessory gland ducts distinct, far apart from one another (Fig. 5C). Tegmen largely membranous, particularly weak and instable on apical third, usually broadly rounded, lateral margins with small rounded projections, param- 


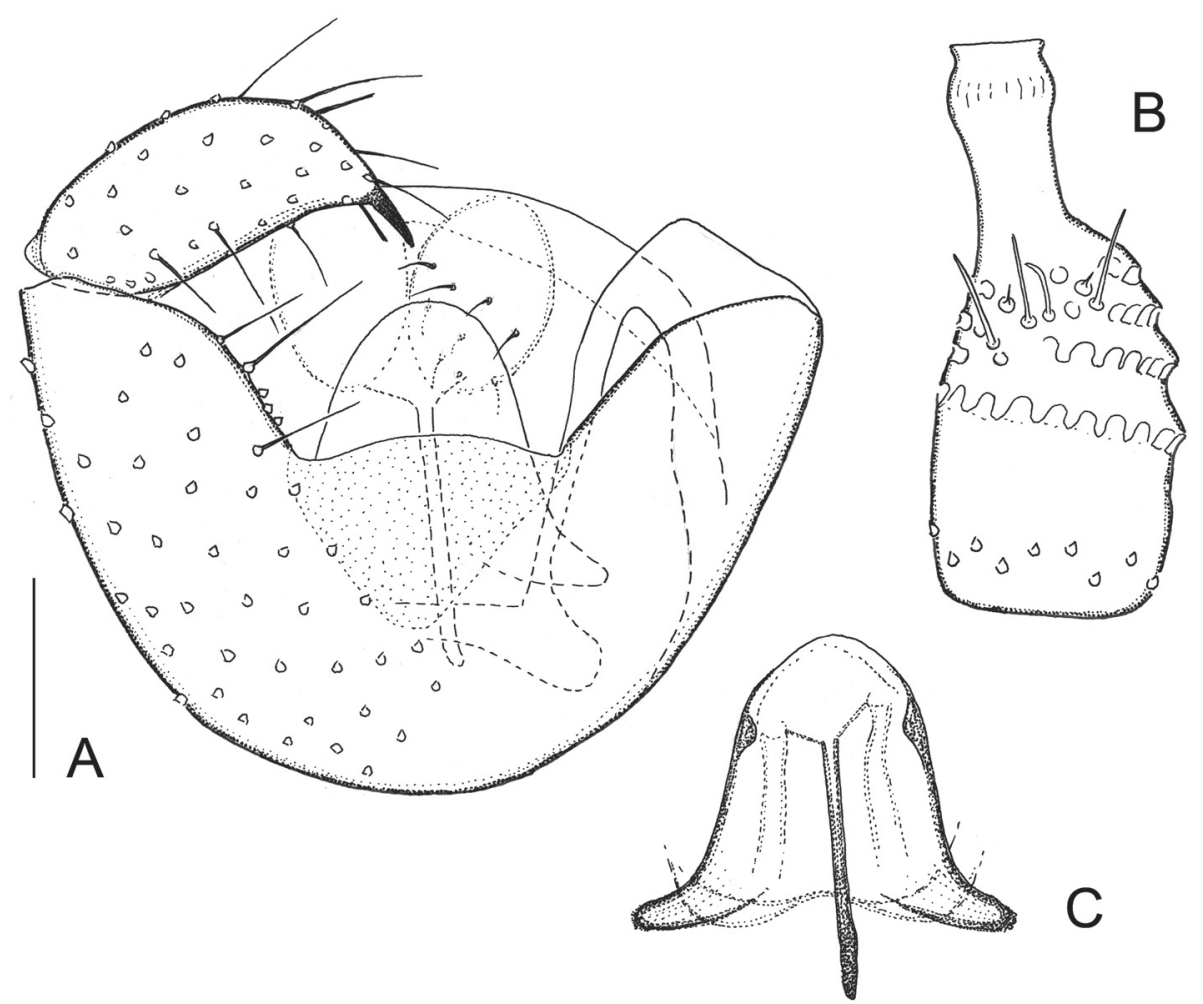

Fig. 5: Pseudomonardia dorani sp. n., male. - A: Terminalia, ventral view; - B: Fourth antennal flagellomere, lateral view; - C: Ejaculatory apodeme and tegmen, ventral view. Scale bar $=0.05 \mathrm{~mm}$.

eral apodemes slightly sclerotized (Fig. 5C). Cerci with short setae (Fig. 5A). St10 present as very weak membranous double lobe with few microtrichia, not always visible (not figured).

Female and immature stages: Unknown.

\section{Discussion:}

Presence of the tenth sternite in this species is unexpected, as it was thought generally lacking in Pteridomyiini. Considering it is barely perceivable in $P$. dorani, and there only in some of the specimens, its presence in other Pteridomyiini might have been overlooked in the past. Anyway, this character state is adequately described for Pteridomyiini as "sternite 10 usually absent, occasionally present as very weak, sparsely microtrichose double lobe”.

\section{Etymology:}

This species is named after Dr Niall Doran, University of Tasmania, School of Zoology, who co-organized the invertebrate sampling at Mount Weld (Mount Weld Altitudinal Transect) in 2001/2002. The samples from this transect are a major source of specimens for our studies.

\section{Types:}

Holotype: Male, Australia, Tasmania, Warra LTER site, Manuka Road, 1 March 2005, Malaise sample FT35685, R. BASHFORD (in AMS). Paratypes: 2 males, same data as the holotype; 1 male, Warra LTER site, Mt Weld, 100 m a.s.l., 27 Feb. 2001, Malaise sample FT19, N. Doran \& R. 
BASHFOrD; 1 male, same locality, 30 March 2001, sample FT109; 1 male, same locality, 27 Feb. 2002, sample FT5923 (in AMS and SDEI).

Other material.

1 male, Tasmania, Southwest National Park, Wedge Creek, 21 Feb.-1 March 2006, N. Jönsson, T. MaLm \& D. Williams; 1 male, Tasmania, Hartz Mountains National Park, Esperanza Creek near Lake Esperanza, 18-28 Feb. 2006, N. Jönsson, T. Malm \& D. Williams; 2 males, Central Plateau, near Arthur's Lake, gravel road from road B51 to Little Lake, 25. Feb.-4 March 2006, N. Jönsson, T. Malm \& D. Williams (in NHRS).

\section{Pseudomonardia niklasi JASCHHOF sp. n.}

(Fig. 6A-C)

\section{Diagnosis:}

The following character states in combination are diagnostic. The gonostyli have a strongly convex outer margin and a fine apical spine; the gonocoxite emargination is shallow and evenly rounded; and the tegmen apex is slightly constricted (Fig. 6A).

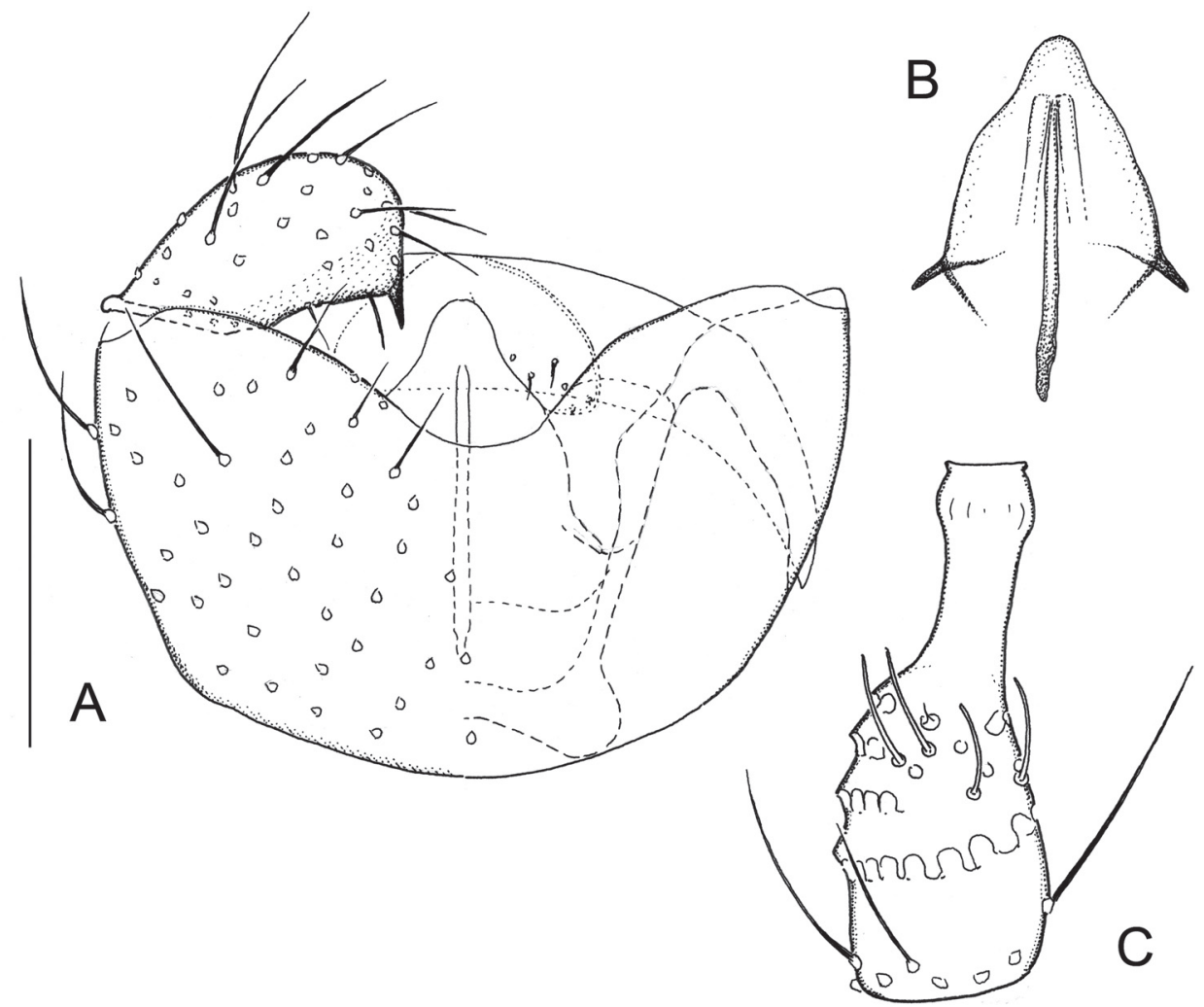

Fig. 6: Pseudomonardia niklasi sp. n., male. - A: Terminalia, ventral view; - B: Ejaculatory apodeme and tegmen, ventral view; - C: Fourth antennal flagellomere, lateral view. Scale bar $=0.05 \mathrm{~mm}$. 


\section{Description:}

Male. Body size: 0.8-0.9 mm. Head: Postfrons asetose. Eye bridge 3-4 ommatidia long. 5-6 postocular bristles. Neck of fourth antennal flagellomere shorter than node; node with 1 single to double whorl of setae subbasally, 1 complete and 3 incomplete whorls of long sensory hairs, several hair-shaped translucent sensilla on apical half (Fig. 6C). Maxillary palpus 4-segmented, long and slender, fourth segment much longer than third.

Wing: ApicR1 = 2.5-3.0 times the length of Rs. R5 without ventral setae. Legs: Pretarsal claws with 3 fine teeth behind subapical swelling. Empodia reduced to a few hairs.

Terminalia: Tg9 subtrapezoid, evenly setose (Fig. 6A). Gonocoxites with shallow, evenly rounded, U-shaped emargination ventrally; antGA short and thick (Fig. 6A). Gonostylus thick, outer margin strongly convex, 1 fine pointed spine apically accompanied by 1-2 short stiff subapical bristles (Fig. 6A). Ejaculatory apodeme thin, slightly longer than tegmen (Fig. 6B). Accessory gland ducts distinct (Fig. 6B). Tegmen membranous, as long as wide, slightly constricted apically, parameral apodemes delicate, sclerotized (Fig. 6B). Cerci with short setae (Fig. 6A).

Female and immature stages. Unknown.

\section{Etymology:}

This species is named after Niklas Jönsson of Naturhistoriska Riksmuseet Stockholm, Department of Entomology, who was one of the participants of the Swedish entomological expedition to Tasmania in 2006. Many of the specimens studied here have been collected by his expedition team.

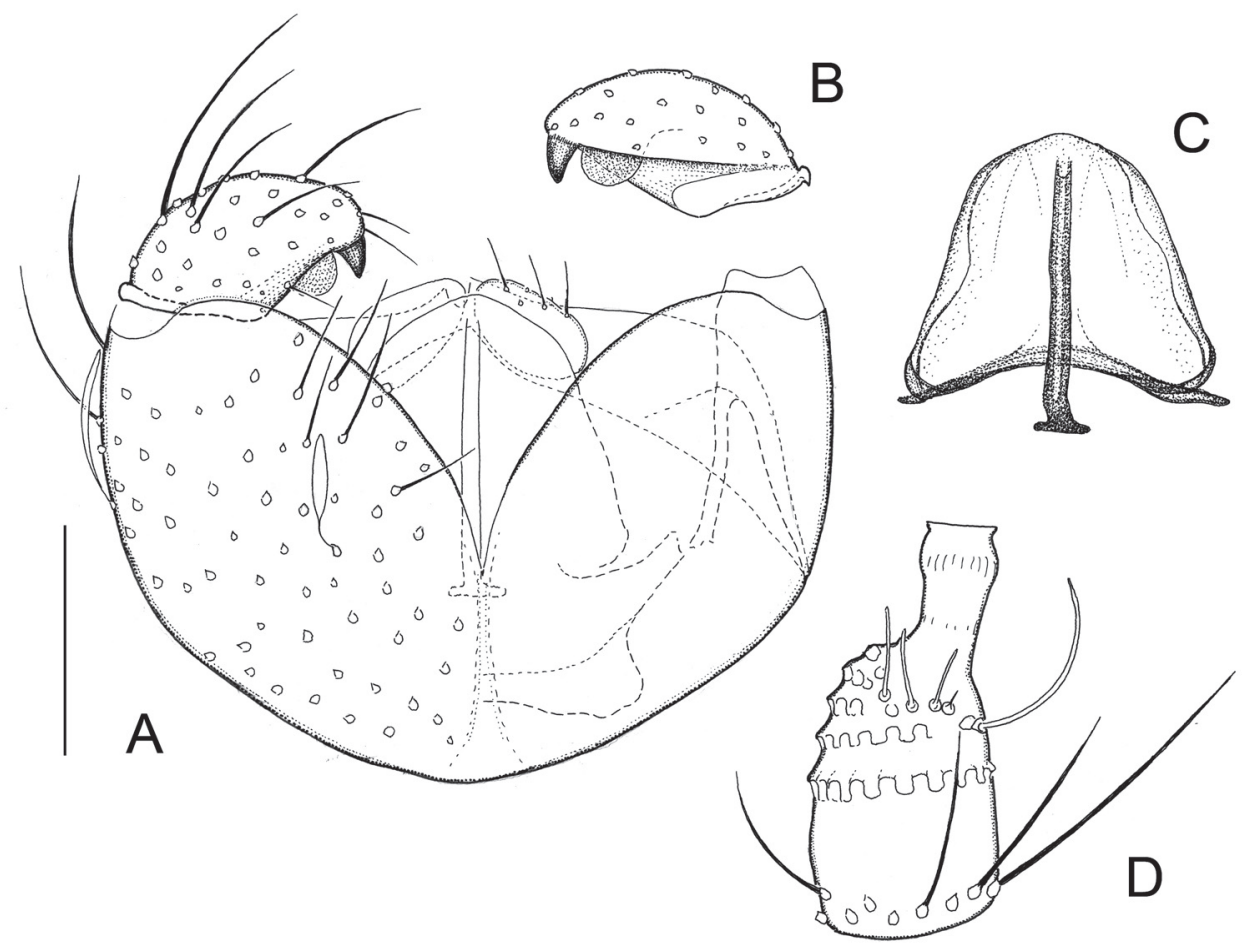

Fig. 7: Pseudomonardia tobiasi sp. n., male. - A: Terminalia, ventral view; - B: Gonostylus, dorsal view; - C: Ejaculatory apodeme and tegmen, ventral view; - D: Fourth antennal flagellomere, lateral view. Scale bar $=0.05 \mathrm{~mm}$. 


\section{Types:}

Holotype: Male, Australia, Tasmania, Warra LTER site, Manuka Road, 1 March 2005, Malaise sample FT35684, R. BASHFORD (in AMS). Paratypes: 1 male, same data as the holotype; 2 males, same data but samples FT35682 and FT35685; 1 male, Warra LTER site, Mt Weld, $100 \mathrm{~m}$ a.s.l., 30 March 2001, Malaise sample FT109, N. Doran \& R. BASHFord; 1 male, Tasmania, Southwest National Park, near road C607 and Creepy Crawly Walk, 570 m a.s.l., 21 Feb.-1 March 2006, N. Jönsson, T. Malm \& D. Williams (in AMS, NHRS and SDEI).

\section{Pseudomonardia tobiasi JASCHHOF sp. n.}

(Fig. 7A-D)

\section{Diagnosis:}

This is the only Pseudomonardia species in which the gonostyli bear two spines, a pointed spine apically and a plate-like, rounded spine dorsosubapically (Fig. 7A-B). The V-shaped gonocoxite emargination (Fig. 7A) is shared with $P$. dawnae sp. n. (see next) and $P$. glacialis JAsCHHOF, 2003 from New Zealand, both with a single spine on the gonostylus apex.

\section{Description:}

Male. Body size: 0.9-1.1 mm. Head: Postfrons asetose. Eye bridge 2-3 ommatidia long laterally and 3-4 ommatidia dorsally. 8-12 postocular bristles. Neck of fourth antennal flagellomere clearly shorter than node; node with 1 single to double whorl of setae subbasally, 1 complete and 3-4 incomplete whorls of long sensory hairs, several hair-shaped translucent sensilla on apical half (Fig. 7D). Maxillary palpus 4-segmented, fourth segment longer than third.

Wing: ApicR1 = 3.0-4.0 times the length of Rs. R5 without ventral setae. Legs: Pretarsal claws with 3 teeth behind subapical swelling. Empodia as long as claws.

Terminalia: Tg9 subtrapezoid, much shorter medially than laterally (Fig. 7A), evenly setose dorsally, with weak pubescent lobes ventrolaterally. Gonocoxites with deep V-shaped emargination ventrally; antGA short and thick (Fig. 7A). Gonostylus much broader basally than apically, excavated medially, 1 thick pointed spine apically, 1 plate-like rounded spine dorsosubapically, the latter very thin and thus often hardly visible (Fig. 7A-B). Ejaculatory apodeme as long as tegmen, slightly widened basally, accessory gland ducts not visible (Fig. 7C). Tegmen largely membranous, almost as long as wide, slightly tapered towards broadly rounded apex, parameral apodemes sclerotized (Fig. 7C). Cerci with short setae (Fig. 7A).

Female and immature stages: Unknown.

\section{Etymology:}

This species is named after Tobias Malm, Ph.D. student with the Naturhistoriska Riksmuseet Stockholm, Department of Entomology, who was also a member of the 2006 expedition to Tasmania.

\section{Types:}

Holotype: Male, Australia, Tasmania, Warra LTER site, Manuka Road, 2 April 2007, Malaise sample FT40220, R. BASHFOrD (in AMS). Paratypes: 1 male, same locality as the holotype but 17 March 2004, sample FT30518; 2 males, same locality but 19 May 2004, sample FT30632; 1 male, same locality but 1 July 2005, sample FT36767; 1 male, same locality but 7 Dec. 2007, sample FT44146 (in AMS and SDEI). 


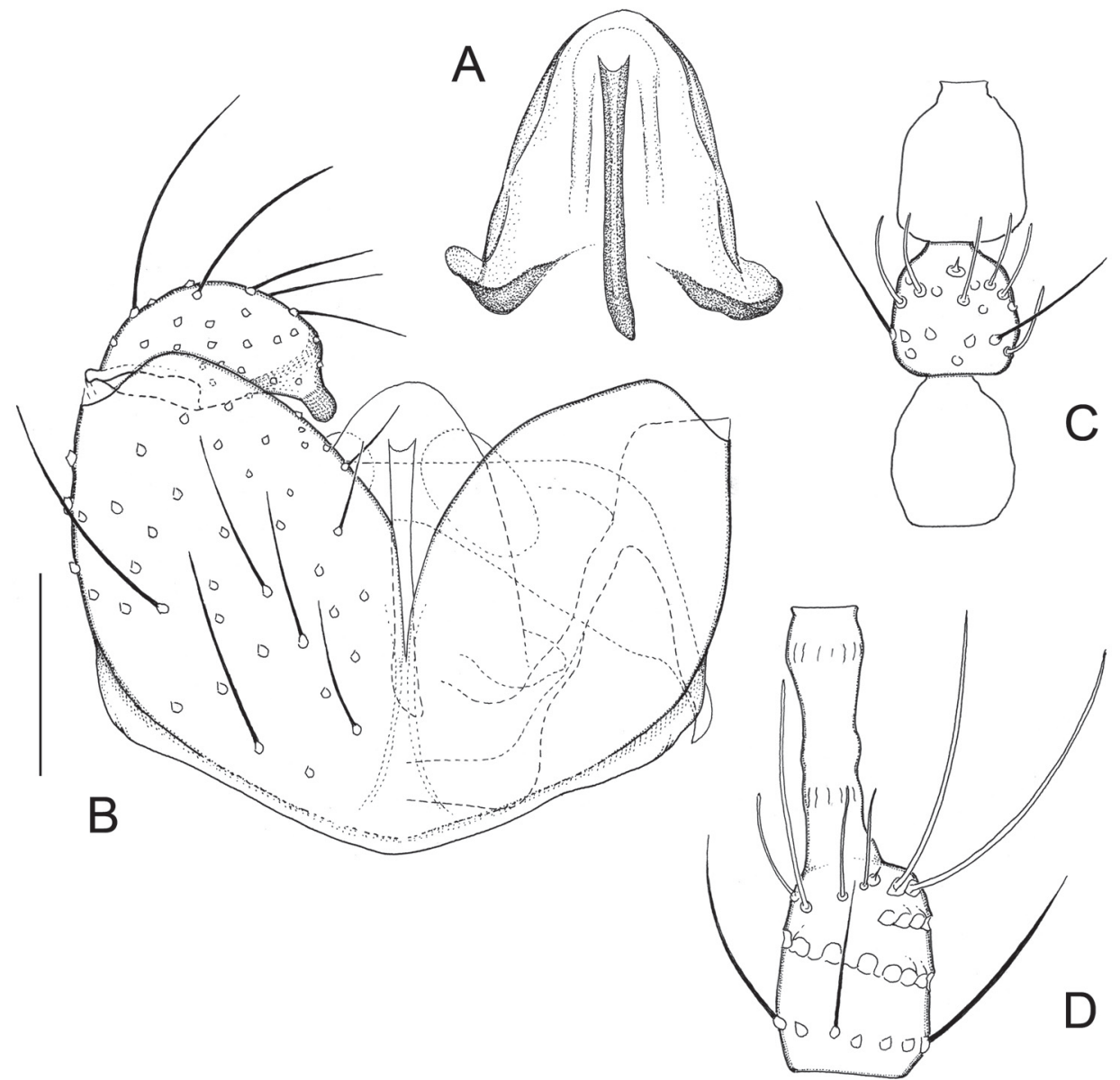

Fig. 8: Pseudomonardia dawnae sp. n. - A: Ejaculatory apodeme and tegmen, ventral view; - B: Male terminalia, ventral view; - C: Female antennal flagellomeres 3-5, lateral view; - D: Male antennal flagellomere 4, lateral view. Scale bar $=0.05 \mathrm{~mm}$.

\section{Pseudomonardia dawnae JASCHноғ sp. n.}

(Fig. 8A-D)

\section{Diagnosis:}

Only Pseudomonardia dawnae and P. pallida Jaschноғ, 2003 from New Zealand have 3-segmented maxillary palpi. The gonostyli of $P$. dawnae bear an apical spine, whereas the gonostyli of P. pallida are spineless.

\section{Description:}

Male. Body size: 1.0-1.1 mm. Head: Postfrons asetose. Eye bridge 1-2 ommatidia long laterally and 3-4 ommatidia dorsally. 5-8 postocular bristles. Neck of fourth antennal flagellomere longer than node; node with 1 single whorl of setae subbasally, 1 complete and 2 incomplete whorls of long sensory hairs, several hair-shaped translucent sensilla on apical half (Fig. 8D). Maxillary palpus 3-segmented, third segment longer than second. 
Wing: ApicR1 = 2.0-3.0 times the length of Rs. R5 without ventral setae. Legs: Pretarsal claws with 3 fine teeth behind subapical swelling. Empodia as long as claws.

Terminalia: $\operatorname{Tg} 9$ subtrapezoid, much shorter medially than laterally (Fig. 8B), evenly setose dorsally, with weak pubescent lobes ventrolaterally. Gonocoxites with deep V-shaped emargination ventrally; antGA vestigial (Fig. 8B). Gonostylus small, tapered towards apex, 1 flat rounded spine apically accompanied by 2 short stiff subapical bristles, another such bristle on outer margin (Fig. 8B). Ejaculatory apodeme as long as tegmen, accessory gland ducts distinctive (Fig. 8A). Tegmen largely membranous, about as long as wide, slightly tapered towards rounded apex, parameral apodemes broad, sclerotized (Fig. 8A). Cerci with short setae (Fig. 8B).

Female. Body size: $1.1 \mathrm{~mm}$. Head: Antenna with 9 flagellomeres, apical flagellomere constricted, fourth flagellomere with very short neck, node with 1 whorl of hair-shaped translucent sensilla basally, 1 whorl of setae subbasally, numerous hair-shaped translucent sensilla scattered on distal half (Fig. 8C). First segment of maxillary palpus swollen.

Legs: Fifth tarsomeres twice a long as fourth tarsomeres, with sole of short stiff blunt-tipped setae.

Terminalia: 2 small globular sclerotized spermathecae. Basicercus and disticercus subequal in length.

Immature stages: Unknown.

\section{Etymology:}

This species is named after Dawn Wiliams, Naturhistoriska Riksmuseet Stockholm, Research Division Directorate, who joined the 2006 expedition team to Tasmania.

Types:

Holotype: Male, Australia, Tasmania, Warra LTER site, Manuka Road, 19 May 2004, Malaise sample FT30632, R. BASHFord (in AMS). Paratypes: 1 male, same data as the holotype but sample FT30634; 1 male, same locality but 1 May 2003, sample FT29026; 2 males, 1 female, Tasmania, Blackwood Creek, eucalypt plantation, 29 Nov.2007, Malaise trap, R. BASHFORD (in AMS and SDEI).

\section{Genus Hintelmannomyia JASCHHOF gen. n.}

Type species: Hintelmannomyia aestimata JaschHof sp. n., described below.

\section{Diagnosis:}

Based on male adults, females and immatures are not known. The new genus differs from other Pteridomyiini by male genitalic characters. The gonocoxites are fused ventrally over their entire length, leaving only a vestigial emargination on the apical margin (Fig. 9C). The gonostyli bear a flat apical spine that is unusually large and bilobed (Fig. 9C).

\section{Description:}

Male. Body size: $>1.0 \mathrm{~mm}$. Head: Postfrons asetose. 3 ocelli. Occiput densely covered with scales intermingled with large setae. 1 row of postocular bristles. Eye bridge complete. Antennal scape and pedicel subequal in size, both with scales and setae. 12 flagellomeres, nodes with crenulate whorls of sensory hairs and hair-shaped translucent sensilla on apical half (Fig. 9B). Clypeus large. Maxillary palpus 4-segmented, first segment bulbous, with hair-shaped translucent sensilla, 
second to fourth segments elongate-subcylindrical, gradually increasing in length, with scales and setae including some short, stiff setae.

\section{Thorax:}

As typical of Micromyidi (JaschHof \& JaschHof 2009: fig. 14B). Scutum and scutellum with scales and setae, otherwise asetose. Wing: As typical of Micromyidi (JaschноF \& Jaschноғ 2009: fig. 15F). Dorsal setae on basR1, apicR1, Rs, r-m, and CuA-stem, no ventral setae. Membrane somewhat smoky, with dense microtrichia and setae on both sides. Pattern of sensory buds: apicR1, 3; Rs, 1; r-m, 1 (dislocated to R5 in one of the wings); R5 medially/distally, 2. Halter club-shaped, stem shorter than node, both densely covered with scales. Legs: Densely clothed in scales and setae. Pretarsal claws subrectangular, distal arm longer than proximal arm, toothed. Empodia reduced.

Preabdomen: Pleura of segments 1-8 with scales. Both tergum 1 and sternum 1 asetose, membranous. Terga and sterna of segments $2-8$ at least partly sclerotized, with scales and setae. Tergal plaques 0/2/2/2/1/1/0/0. Terminalia: Fig. 9A, C-D. Tg9 short, with indistinct basal margin. Gonocoxites broadly fused ventrally, emargination on ventroapical margin vestigial. AntGA developed. Gonostylus with flat, unusually large, bilobed apical spine. Ejaculatory apodeme present, ducts of accessory glands well visible. Tegmen largely membranous. Cerci present as pair of short ovate lobes attached to tg9. St10 absent.

\section{Discussion:}

The new genus shows all the characters typical of Pteridomyiini (cf. JaschHof \& JasChHof 2003: 109ff.), so doubtless belongs to this tribe. The three pteromyiine genera now known differ mainly in male genitalic structures, which in Hintelmannomyia deviate more strongly from the micromyid ground pattern (JaschHof \& JasChHof 2009: fig. 18) than in Pteridomyia or Pseudomonardia. It is certainly too early to discuss intergeneric relationships, as we are just beginning to ascertain pteridomyiine generic diversity.

\section{Etymology:}

This new genus is named to honour Mrs Elisabeth Hintelmann, Munich, Germany, and her late husband, Mr Robert J. H. Hintelmann for their furthering of zoosystematics. Mrs Hintelmann's substantial support was crucial for the continuation of our taxonomic studies of Tasmanian Cecidomyiidae.

\section{Hintelmannomyia aestimata JASCHHOF sp. n.}

(Fig. 9A-D)

\section{Description:}

Male. Body size: 1.1 and 1.5 mm. Head: Eye bridge (2-)3-4 ommatidia long. 6 and 14, respectively, postocular bristles. Antennal flagellomeres elongate. Neck of fourth antennal flagellomere shorter than node; node with 1 double whorl of moderately long setae subbasally, 1 complete and 3-4 incomplete whorls of long sensory hairs, several hair-shaped translucent sensilla on apical half (Fig. 9B). First and second segments of maxillary palpus with hair-shaped translucent sensilla, first segment somewhat swollen, fourth segment much longer than third.

\section{Thorax:}

Scutum densely covered with scales and lateral setae. Wing: ApicR1 = 4.5 times the length of Rs. Legs: Distal arm of pretarsal claws with 4 fine teeth behind subapical swelling. Empodia 1/3 as long as claws. 
Preabdomen: Terga 2-4 with large membranous portions anteromedially, sclerotized elsewhere. Terminalia: $\mathrm{Tg} 9$ evenly sparsely setose, on apical margin apparently with small, rounded medial lobe (Fig. 9A). Gonocoxites densely covered with scales and setae ventrally except for small asetose portion apicocentrally, ventroapical margin membranous medially, very slightly emarginated, slightly bulged on both sides of emargination; antGA short and narrow (Fig. 9C). Gonostylus with setae of various sizes, 1 large flat bilobed spine apically, outer margin convex (Fig. 9C). Ejaculatory apodeme poorly sclerotized, shorter than tegmen (Fig. 9D). Tegmen small, tapered towards narrowly rounded apex, parameral apodemes sclerotized (Fig. 9D). Tegmen apex wrapped by cerci, latter with short setae (Fig. 9C).

\section{Variation:}

The paratype specimen is smaller in size, has only 11 flagellomeres on one of the antennae, a shorter eye bridge, much fewer postocular bristles, and narrower wings. It is obviously an atrophied individual that might have developed under suboptimal conditions. Such individuals are not unusual among Micromyinae.

\section{Etymology:}

The name is Latin, meaning esteemed.

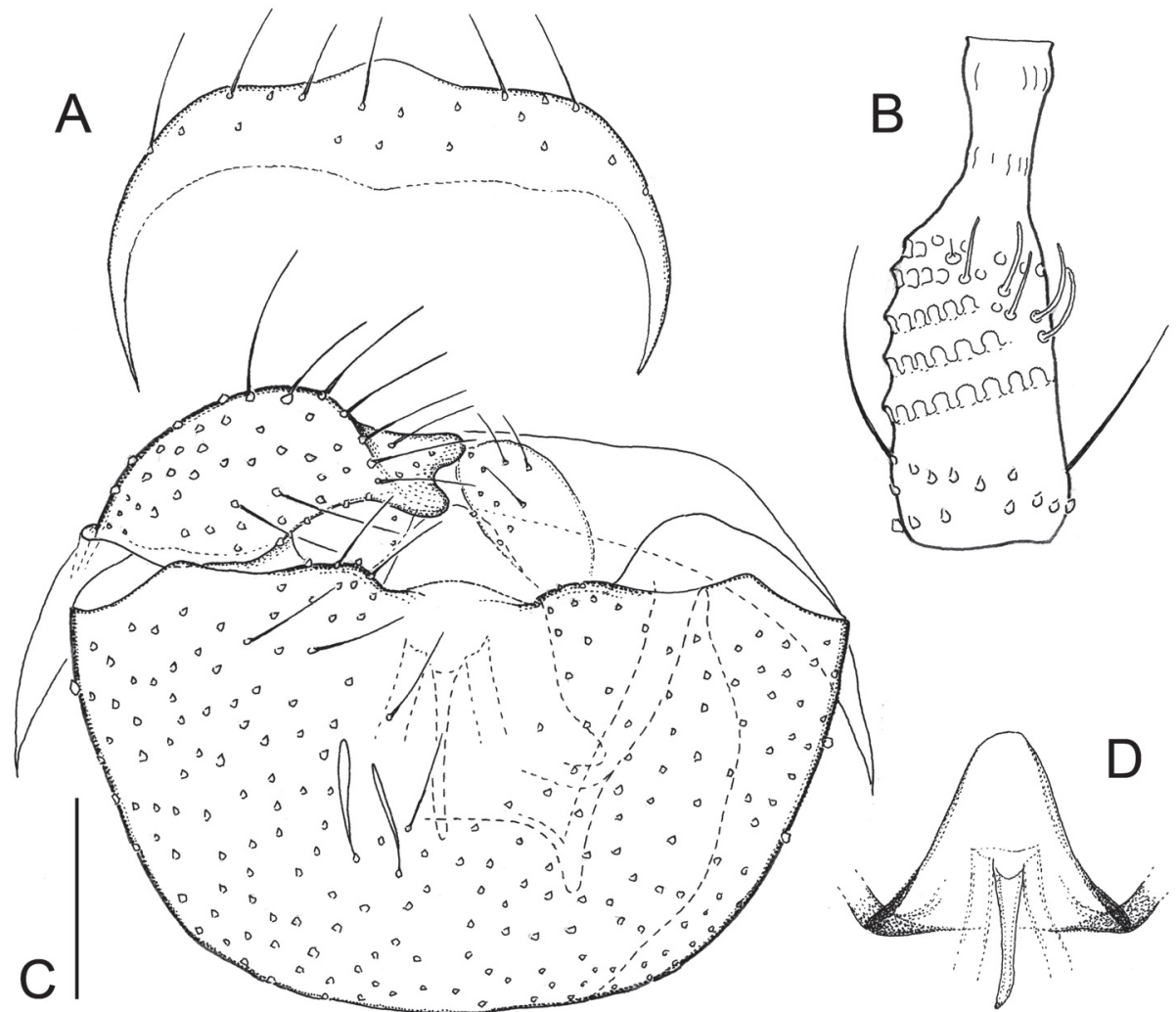

Fig. 9: Hintelmannomyia aestimata gen. et sp. n., male. - A: Ninth tergite, ventral view; - B: fourth antennal flagellomere, lateral view; - C: terminalia, ventral view; - D: ejaculatory apodeme and tegmen, ventral view. Scale bar $=0.05 \mathrm{~mm}$. 


\section{Types:}

Holotype: Male, Australia, Tasmania, Warra LTER site, Manuka Road, 14 April 2000, Malaise sample FT28646, R. BASHFord (in AMS). Paratype: 1 male, Tasmania, Southwest National Park, Wedge Creek, 330 m, 21 Feb.-1 March 2006, by Malaise trap, N. Jönsson, T. Malm \& D. Williams (in NHRS).

\section{Acknowledgements}

Specimen collection in Tasmania was made possible through a Warra Small Project Grant for M.J. by Forestry Tasmania, which is gratefully acknowledged. The Entomology Department, Swedish Museum of Natural History, Stockholm, generously allowed us to study the Cecidomyiidae from their 2006 expedition to Tasmania. Dr David Yeates of ANIC and Dr Michel BaYLac of Muséum National d'Histoire Naturelle, Paris is thanked for the loan of SKusE's type specimen of Campylomyza grandiuscula. Dr Raymond J. GAGNÉ, research entomologist emeritus with the Systematic Entomology Laboratory, USDA, National Museum of Natural History Washington, D. C., U.S.A., and Dr Frank Menzel, Senckenberg Deutsches Entomologisches Institut, Müncheberg, read and commented on the manuscript.

\section{Literature}

Jaschrof, M. 2010: New species of Peromyia from Tasmania, with a revision of Schiner's and Skuse's types of Australian Micromyinae (Diptera: Cecidomyiidae). - Beiträge zur Entomologie 60 (1): 33-55

Jaschнof, M. \& Jaschнof, C. 2003: Wood midges of New Zealand (Cecidomyiidae, Lestremiinae). Part I: Introductory notes and tribes Lestremiini, Strobliellini, Campylomyzini and Pteridomyiini JaschHof trib. nov. - Studia dipterologica 10 (1): 97-132.

Jaschiof, M. \& Jaschiof, C. 2004: Wood midges of New Zealand (Cecidomyiidae, Lestremiinae). Part III: Tribe Peromyiini and remarks on the composition, origin and relationships of the fauna as a whole. - Studia dipterologica 10 (2003) (1): 97-132.

Jaschrof, M. \& Jaschrof, C. 2009: The wood midges (Diptera: Cecidomyiidae: Lestremiinae) of Fennoscandia and Denmark. - Studia dipterologica Supplement 18: 1-333.

Skuse, F. A. A. 1890: Diptera of Australia. Nematocera - Supplement I. - Proceedings of the Linnean Society of New South Wales (2nd series) 5: 373-412, plate 16.

Authors' addresses:

Dr Mathias JaschHof

Senckenberg Deutsches

Entomologisches Institut

Eberswalder Str. 90

15374 Müncheberg

Germany

e-mail: Mathias.Jaschhof@senckenberg.de
Subject editor:

Catrin JaschHoF

Thälmann-Ring 64

17491 Greifswald

Germany

e-mail: cjaschhof@yahoo.de
Dr. F. MenZel 